PAPER

\section{Conservation of quantum efficiency in quantum well intermixing by stress engineering with dielectric bilayers}

To cite this article: Seval Arslan et al 2018 Semicond. Sci. Technol. 33025001

View the article online for updates and enhancements.
Related content

- Impurity-free quantum well intermixing for
$\frac{\text { large optical cavity high-power laser diode }}{\text { structures }}$
Abdullah Kahraman, Emre Gür and Atilla
Aydnl
- Investigations of impurity-free vacancy
$\frac{\text { disordering in (Al)InGaAs(P)/InGaAs }}{\text { quantum wells }}$
S C Du, L Fu, H H Tan et al.
- Fabrication of wavelength-shifted
$\frac{\text { In0.2Ga0.8As/GaAs MQW laser diodes by }}{\text { IFVD at different thermal annealing }}$
$\frac{\text { temperatures }}{\text { Jae Su Yu, Jin Dong Song, Yong Tak Lee }}$
et al.

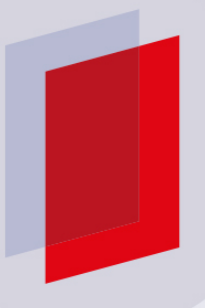

\section{IOP ebooks}

Bringing you innovative digital publishing with leading voices

to create your essential collection of books in STEM research.

Start exploring the collection - download the first chapter of every title for free. 


\title{
Conservation of quantum efficiency in quantum well intermixing by stress engineering with dielectric bilayers
}

\author{
Seval Arslan ${ }^{1}$, Abdullah Demir $^{1}{ }^{(0)}$, Seval Şahin $^{2}$ and Atilla Aydınlı ${ }^{3}$ \\ ${ }^{1}$ Department of Physics, Bilkent University, 06800, Ankara, Turkey \\ ${ }^{2}$ Department of Physics, Anadolu University, 26470, Eskişehir, Turkey \\ ${ }^{3}$ Department of Electrical and Electronics Engineering, Uludağ University, 16059, Bursa, Turkey \\ E-mail: abdullah.demir@bilkent.edu.tr and atillaaydinli@uludag.edu.tr
}

Received 26 October 2017, revised 27 November 2017

Accepted for publication 8 December 2017

Published 5 January 2018

\begin{abstract}
In semiconductor lasers, quantum well intermixing (QWI) with high selectivity using dielectrics often results in lower quantum efficiency. In this paper, we report on an investigation regarding the effect of thermally induced dielectric stress on the quantum efficiency of quantum well structures in impurity-free vacancy disordering (IFVD) process using photoluminescence and device characterization in conjunction with microscopy. $\mathrm{SiO}_{2}$ and $\mathrm{Si}_{x} \mathrm{O}_{2} / \mathrm{SrF}_{2}$ (versus $\mathrm{SrF}_{2}$ ) films were employed for the enhancement and suppression of QWI, respectively. Large intermixing selectivity of $75 \mathrm{~nm}(125 \mathrm{meV})$, consistent with the theoretical modeling results, with negligible effect on the suppression region characteristics, was obtained. $\mathrm{Si}_{x} \mathrm{O}_{2}$ layer compensates for the large thermal expansion coefficient mismatch of $\mathrm{SrF}_{2}$ with the semiconductor and mitigates the detrimental effects of $\mathrm{SrF}_{2}$ without sacrificing its QWI benefits. The bilayer dielectric approach dramatically improved the dielectric-semiconductor interface quality. Fabricated high power semiconductor lasers demonstrated high quantum efficiency in the lasing region using the bilayer dielectric film during the intermixing process. Our results reveal that stress engineering in IFVD is essential and the thermal stress can be controlled by engineering the dielectric strain opening new perspectives for QWI of photonic devices.
\end{abstract}

Keywords: quantum well intermixing, impurity free vacancy disordering, semiconductor laser, stress engineering, quantum efficiency

(Some figures may appear in colour only in the online journal)

\section{Introduction}

Even though record high output powers have been demonstrated for semiconductor lasers [1-4], one of the limitations for high laser output power operation is the catastrophic optical mirror damage (COMD) [5]. Among various facet engineering techniques to suppress COMD, quantum well intermixing $(\mathrm{QWI})$ is preferred because it is easier to implement and laser design and COMD suppression windows can be realized independently [6-9]. QWI has been exploited for the monolithic integration of tunable semiconductor lasers, low-loss waveguides, modulators and photodetectors [10-12].
Effective bandgap of the QW is enlarged by interdiffusion of the atoms across it in the QWI window so that losses due to interband absorption in the output window region are substantially reduced or even eliminated. One of the most promising QWI approaches is impurity-free vacancy disordering (IFVD) since it does not introduce additional impurities and hence eliminates free carrier absorption losses and, in the ideal case, preserves epitaxial quality [6]. The IFVD process requires the deposition of a dielectric cap to control the degree of intermixing to be enhanced or suppressed with the appropriate dielectric materials and annealing temperature $[7,9,13-17]$. The vacancy disordering is mainly affected by 
the dielectric film and the thermal stress executed by the dielectric film on the semiconductor [18].

Studies on IFVD have focused more on wavelength control or fabrication of multiwavelength lasers $[7,15,16]$. Work with an emphasis on achieving large intermixing selectivity with minimal wavelength and quantum efficiency disruption in the suppression region has so far been scarce with limited disclosure of the applied technique [19-21]. Device lifetime and operational powers of high power laser diodes with a non-absorbing output window were reported to be highly correlated with the amount of QWI selectivity, i.e. the PL wavelength (bandgap) shift difference $\Delta \lambda(\Delta E)$ between the gain and IFVD window regions [19, 20]. Naito et al demonstrated that semiconductor lasers with larger $\Delta E$ operate at higher output power with longer device lifetime and stable operation of more than $5000 \mathrm{~h}$ at $20 \mathrm{~W}$ output was achieved for $9 \mathrm{xx} \mathrm{nm}$ broad area laser diodes using IFVD windows with $\Delta E=100 \mathrm{meV}$ [20]. Intermixing by $\mathrm{SiO}_{2}$ and suppression by $\mathrm{Si}_{x} \mathrm{O}_{2}(x>1)$ or $\mathrm{Si}_{3} \mathrm{~N}_{4}$ caps offers high quantum efficiency and surface quality but lacks good QWI selectivity [13, 16]. Intermixing by $\mathrm{SiO}_{2}$ and suppression under $\mathrm{SrF}_{2}$ caps were demonstrated with good QWI selectivity; however, $\mathrm{SrF}_{2}$-capped laser devices suffered from a penalty on operational voltage, threshold current, quantum efficiency [22-24] and some surface damage was apparent after annealing [7], which needs to be avoided for reliable operation of these devices. The surface defects indicate degradation of the epitaxial material quality and under high injection current densities defects can migrate into the active region and promote the non-radiative recombination, which increases threshold current and decreases the quantum efficiency and reliable output power of the high power laser diodes. Understanding and solving these issues are keys to attain high-performance optoelectronic devices with reliable long operation lifetimes.

In this study, we investigated the effect of thermal stress on the quantum efficiency of the devices using $\mathrm{SiO}_{2}$ for QWI and $\mathrm{SrF}_{2}$ single-layer versus $\mathrm{Si}_{x} \mathrm{O}_{2} / \mathrm{SrF}_{2}$ bilayer for QWI suppression with large selectivity. $\mathrm{Si}_{x} \mathrm{O}_{2}$ layer compensates for the large thermal expansion coefficient mismatch of $\mathrm{SrF}_{2}$ with the semiconductor and hence the bilayer approach mitigates the detrimental effects of $\mathrm{SrF}_{2}$ without sacrificing its QWI selectivity benefits. By comparing $\mathrm{SrF}_{2}$ and strain-compensated $\mathrm{Si}_{x} \mathrm{O}_{2} / \mathrm{SrF}_{2}$ films, the effect of thermally induced dielectric stress on the epitaxial structure and laser performance were demonstrated. High intermixing selectivity of $75 \mathrm{~nm}(125 \mathrm{meV})$ with negligible effect in the suppression region was obtained using $\mathrm{Si}_{x} \mathrm{O}_{2} / \mathrm{SrF}_{2}$. Utilizing the bilayer dielectric for intermixing suppression, we demonstrate an IFVD process for high power semiconductor lasers with good surface morphology, large QWI selectivity, high quantum efficiency and negligible effect on lasing characteristics. Our results reveal that the thermal stress due to QWI process can be controlled by engineering the dielectric strain and open new perspectives for QWI of photonic devices.

\section{Experimental details}

Laser structure was grown by metalorganic chemical vapor deposition on GaAs. The structure was composed of $3000 \mathrm{~nm}$ $\mathrm{n}$-AlGaAs cladding, $500 \mathrm{~nm} \mathrm{n}$-AlGaAs waveguide, $8 \mathrm{~nm}$ InGaAs QW, $500 \mathrm{~nm}$ p-AlGaAs waveguide, $1000 \mathrm{~nm}$ p-AlGaAs cladding, and finally capped by $100 \mathrm{~nm}$ GaAs contact layer. Plasma enhanced chemical vapor deposition (PECVD) was used for $\mathrm{SiO}_{2}$ and $\mathrm{Si}_{x} \mathrm{O}_{2}$ depositions, and thermal evaporation was implemented for $\mathrm{SrF}_{2}$ deposition process. The refractive indices of the deposited films were measured by spectroscopic ellipsometry as 1.46 for $\mathrm{SiO}_{2}$, 1.57 for $\mathrm{Si}_{x} \mathrm{O}_{2}$ and 1.38 for $\mathrm{SrF}_{2}$ at $633 \mathrm{~nm}$.

Single layer and bilayer films were studied in this work. For the investigation of single layer film effect, $250 \mathrm{~nm}$ thick $\mathrm{SiO}_{2}, \mathrm{Si}_{x} \mathrm{O}_{2}$ and $\mathrm{SrF}_{2}$ dielectric films were used. For comparison of the QWI suppression, $10 \mathrm{~nm} / 30 \mathrm{~nm}$ thick $\mathrm{Si}_{x} \mathrm{O}_{2} / \mathrm{SrF}_{2}$ bilayer films and $30 \mathrm{~nm}$ thick $\mathrm{SrF}_{2}$ film were used. The deposition recipe for $\mathrm{Si}_{x} \mathrm{O}_{2}$ was developed to yield smaller wavelength shifts compared to $\mathrm{SiO}_{2}$ by changing its stoichiometry through modification of flow rates in PECVD [16]. For the multilayer films, two distinct regions were defined, where the first one is for QWI $\left(\mathrm{SiO}_{2}\right)$ and the second is for QWI suppression $\left(\mathrm{SrF}_{2}\right.$ versus $\left.\mathrm{Si}_{x} \mathrm{O}_{2} / \mathrm{SrF}_{2}\right)$. Initially, $250 \mathrm{~nm} \mathrm{SiO}_{2}$ intermixing dielectric was deposited on $(5 \mathrm{~mm}) \times(10 \mathrm{~mm})$ wafer samples and a half of it was etched. Then, either 1-layer $\left(30 \mathrm{~nm}-\mathrm{SrF}_{2}\right)$ or 2-layer $\left(10 \mathrm{~nm}-\mathrm{Si}_{x} \mathrm{O}_{2} / 30 \mathrm{~nm}-\mathrm{SrF}_{2}\right)$ dielectrics were deposited on the whole sample. The side view of the dielectric deposition configuration is shown in figure 1(a1) and (a2). Rapid thermal annealing (RTA) from 860 to $920{ }^{\circ} \mathrm{C}$ for 2 min were carried out in nitrogen ambient by sandwiching the samples between fresh GaAs wafers to prevent out-diffusion of As atoms from the surface of the samples. Extended time annealing (2-6 min) at $880^{\circ} \mathrm{C}$ were also performed to increase the QWI selectivity. After removal of the dielectrics, surface quality was evaluated by optical and atomic force microscopy (AFM). To estimate the amount of QWI, room temperature PL measurements were performed from the top after etching off $\sim 1 \mu \mathrm{m}$ of the epitaxial material to increase PL signal.

Finally, to study the effect of thermally induced dielectric stress on quantum efficiency and other device characteristics, we fabricated broad area high power laser diodes of $(4 \mathrm{~mm}) \times(100 \mu \mathrm{m})$ size with as-grown and RTA processed structures. For RTA processed laser devices, QWI with $250 \mathrm{~nm} \quad \mathrm{SiO}_{2}$ and suppression capping with 2-layer $\left(10 \mathrm{~nm}-\mathrm{Si}_{x} \mathrm{O}_{2} / 10 \mathrm{~nm}-\mathrm{SrF}_{2}\right)$ and 1-layer $\left(10 \mathrm{~nm}-\mathrm{SrF}_{2}\right)$ dielectrics were applied on neighboring emitters on the same bar. $\mathrm{SiO}_{2}$ film was also covered by $\mathrm{Si}_{x} \mathrm{O}_{2} / \mathrm{SrF}_{2}$ films to simplify the processing steps since it does not influence the QWI behavior of $\mathrm{SiO}_{2}$ as confirmed by the PL experiments. Each emitter is covered only by the corresponding dielectric and then the whole wafer was annealed at $880{ }^{\circ} \mathrm{C}$ for $4 \mathrm{~min}$. All dielectric layers were removed before the fabrication process. Ridge waveguides were formed, a dielectric layer $\left(\mathrm{Si}_{3} \mathrm{~N}_{4}\right)$ was deposited to act as an electrical insulator and current injection windows were opened on top of the ridge waveguides. P- and n-metals were deposited and alloyed to form contacts. 

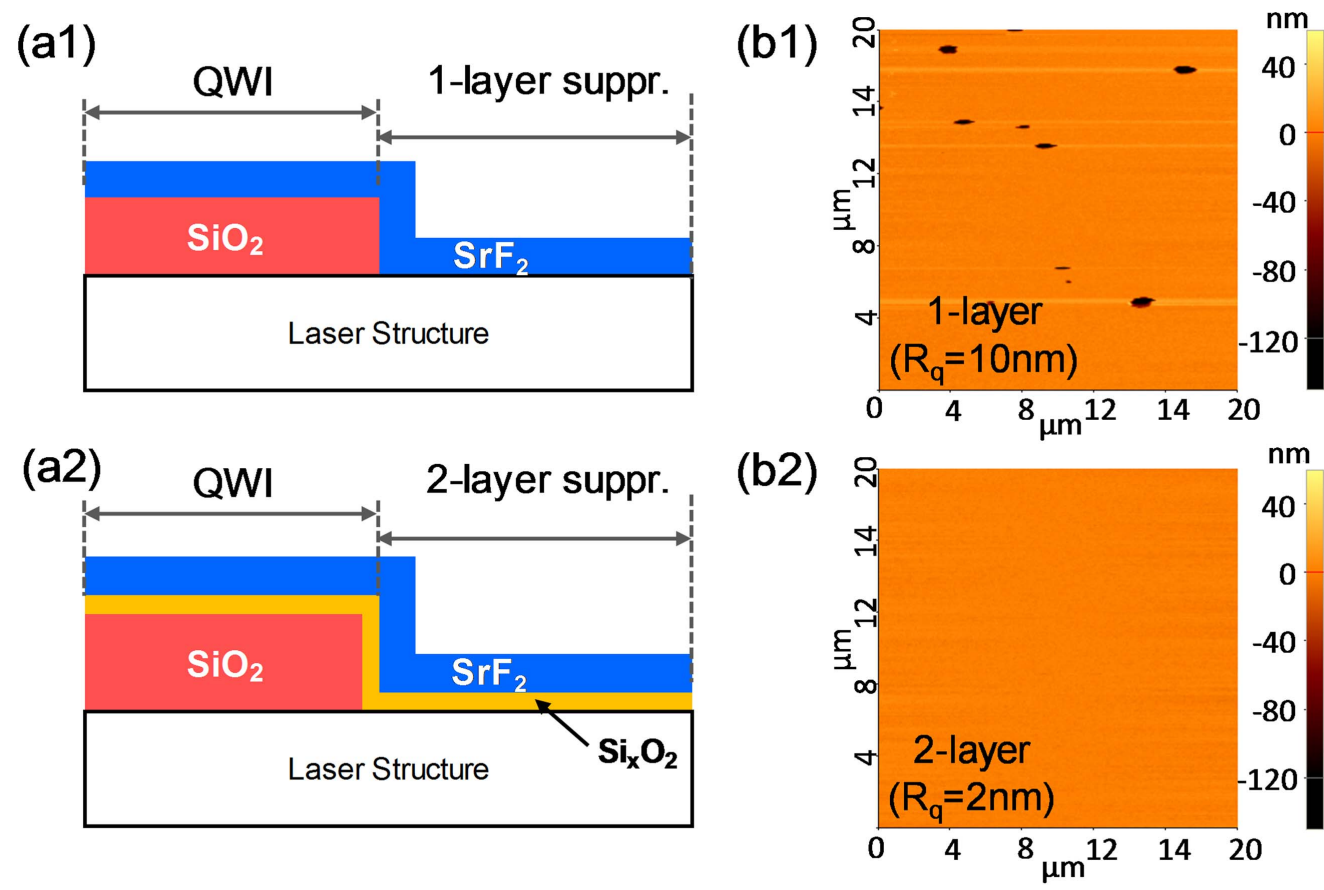

Figure 1. Side view schematic of QWI and suppression configuration investigated in this study using (a1) 1-layer and (a2) 2-layer suppression method. Corresponding top view AFM images of the (b1) 1-layer and (b2) 2-layer deposited surfaces after annealing and etching of dielectrics.

Fabricated lasers were cleaved and tested epi-side up under continuous wave current injection at room temperature.

\section{Results and discussion}

\subsection{Intermixing with single layer versus bilayer dielectrics}

Figures 1(a1) and (a2) illustrate the side view schematic of the QWI $\left(\mathrm{SiO}_{2}\right)$ and suppression regions (1-layer versus 2-layer) on top of the laser epitaxial structure. Due to different thermal stress generated by $\mathrm{SrF}_{2}$ (1-layer) and $\mathrm{Si}_{x} \mathrm{O}_{2}$ films, a straincompensated 2-layer $\left(\mathrm{Si}_{x} \mathrm{O}_{2} / \mathrm{SrF}_{2}\right)$ approach was investigated to understand the influence of thermally induced dielectric stress. The deposition recipe for $\mathrm{Si}_{x} \mathrm{O}_{2}$ was developed to yield smaller wavelength shifts, as indicated previously, in conjunction with $\mathrm{SrF}_{2}$ for QWI suppression and with the purpose of thermal stress reduction. In these configurations, 1-layer or 2-layer suppression films also cover $\mathrm{SiO}_{2}$ that is used for QWI; however, these films do not reduce the QWI amount of the sufficiently thick $(250 \mathrm{~nm}) \mathrm{SiO}_{2}$ film, which was confirmed by PL measurements. Figures 1(b1) and (b2) illustrates the top view AFM images of the suppression region surfaces with 1-layer and 2-layer films after RTA for 2 min at $880^{\circ} \mathrm{C}$ and etching of the dielectrics, where the color bar indicated the depth/height of the surface. Annealing induces structural changes in the $\mathrm{SrF}_{2}$ film and surface damage after its removal was clearly observed consistent with the former observations [7, 21-23] and appeared even for $5 \mathrm{~nm}$ thick $\mathrm{SrF}_{2}$ layer after RTA. The surface damage suggests the stress build-up during thermal annealing of $\mathrm{SrF}_{2}$ and, thus, the occurrence of complete stress relaxation of the induced thermal stress accompanied by the generation of crystal defects. In contrast, good surface morphology comparable to as-grown wafer was observed in 2-layer region as illustrated in figure $1(\mathrm{~b} 2) . \mathrm{Si}_{x} \mathrm{O}_{2}$ layer as thin as $10 \mathrm{~nm}$ used in this study was found to be sufficient to compensate $\mathrm{SrF}_{2}$ induced damage. The rootmean-square roughness $\left(R_{\mathrm{q}}\right)$ of the 1-layer protected surface was $10 \mathrm{~nm}$, whereas 2-layer protected region was improved down to $2 \mathrm{~nm}$.

For semiconductor devices, it is important to identify the structural parameters such as internal strain and thermal stress that eventually control the dislocation density and device performance. It is well known that the internal strain due to lattice mismatch of quantum well structures beyond a critical thickness and mismatch ratio would create misfit dislocations and degrade the device performance [25]. Strain-compensated growth approach provides an efficient way to balance the strain and successful growth of large lattice mismatched quantum well structures [26]. Thermal stress is an intrinsic problem for heat sinks with large thermal expansion coefficient (CTE) mismatch compared to a semiconductor laser deteriorating the reliability and lifetime of devices [27]. The influence of stress on the bandgap of QWs is well known [28] and the impact of dielectric stress on the PL wavelength shift of QWI has been demonstrated [29-31]. During QWI process, the high temperature change modifies the mechanical stress of the semiconductor/dielectric system and this is mainly caused by the CTE mismatch between the semiconductor and dielectric materials. For QWI suppression, $\mathrm{SrF}_{2}$ has so far been one of the best dielectrics for high intermixing selectivity; however, it introduces epitaxial damage and penalty on operational parameters such as voltage, threshold, quantum efficiency making it a non-ideal 
Table 1. Physical parameters of dielectric films and calculated thermal stress values of single layer films on a GaAs substrate.

\begin{tabular}{lcccccc}
\hline Material & $\alpha\left(\mathrm{ppm}^{\circ} \mathrm{C}^{-1}\right)$ & $E_{\mathrm{f}} /\left(1-\nu_{\mathrm{f}}\right)(\mathrm{Gpa})$ & $\sigma_{\text {in }}(\mathrm{GPa})$ & $\Delta \alpha \cdot \Delta T$ & $\sigma_{\text {th }}(\mathrm{GPa})$ & $\sigma_{\text {total }}(\mathrm{GPa})$ \\
\hline $\mathrm{Si}_{x} \mathrm{O}_{2}$ & 1 & 120 & -0.2 & $-0.5 \%$ & +0.6 & +0.4 \\
$\mathrm{SrF}_{2}$ & 28 & 110 & 0 & $+1.8 \%$ & -2.1 & -2.1 \\
$\mathrm{GaAs}$ & 7 & - & - & - & - & - \\
\hline
\end{tabular}

candidate. The mismatch is extensive between $\mathrm{SrF}_{2}$ $\left(\mathrm{CTE} \sim 18 \mathrm{ppm}^{\circ} \mathrm{C}^{-1}\right.$ at $20^{\circ} \mathrm{C}$ and $\sim 31 \mathrm{ppm}^{\circ} \mathrm{C}^{-1}$ at IFVD temperature of around $900{ }^{\circ} \mathrm{C}$ corresponding to effective linear $\mathrm{CTE} \sim 28 \mathrm{ppm}^{\circ} \mathrm{C}^{-1}$ ) [32] and $\mathrm{GaAs}\left(\mathrm{CTE} \sim 7 \mathrm{ppm}^{\circ} \mathrm{C}^{-1}\right)$ [33]. Employing a low CTE dielectric of $\mathrm{Si}_{x} \mathrm{O}_{2}\left(\mathrm{CTE} \sim 1 \mathrm{ppm}^{\circ} \mathrm{C}^{-1}\right)$ [34] in a bilayer configuration of $\mathrm{Si}_{x} \mathrm{O}_{2} / \mathrm{SrF}_{2}$ can compensate the CTE mismatch and hence reduce thermal stress on the epitaxial structure and its associated issues. Thermal stress $\sigma_{\text {th }}$ generated in a thin film on a thick substrate during a thermal treatment with temperature difference $\Delta T$ is given by $\sigma_{\text {th }}=$ $\left[E_{\mathrm{f}} /\left(1-v_{\mathrm{f}}\right)\right] \Delta \alpha \Delta T$, where $E_{\mathrm{f}}$ is the Young modulus, $v_{\mathrm{f}}$ is the Poisson coefficient of the thin film, and $\Delta \alpha$ is the linear thermal expansion coefficient difference between the film and substrate [29]. Table 1 summarizes the physical parameters of the dielectric and GaAs substrate materials that were used in this study. The calculated values are the thermal expansion mismatch $(\Delta \alpha \cdot \Delta T)$, thermal stress $\left(\sigma_{\text {th }}\right)$ and total stress $\left(\sigma_{\text {total }}\right)$ generated during the annealing with $\Delta T \sim+850^{\circ} \mathrm{C}$, which are summarized in table 1 . $\sigma_{\text {in }}$ is intrinsic stress contribution of the dielectrics. At room temperature, the $\mathrm{Si}_{x} \mathrm{O}_{2}$ film is under compressive stress $(-0.2 \mathrm{GPa})$ but it becomes tensile $(+0.4 \mathrm{GPa})$ with thermal expansion mismatch of $-0.5 \%$. For $\mathrm{SrF}_{2}$, the film does not have an intrinsic stress but very high compressive stress $(-2.1 \mathrm{GPa})$ with large thermal expansion mismatch of $+1.8 \%$ is expected at the annealing temperature. The situation is different for 2-layer films, where reduced total stress $(\sim-1.7 \mathrm{GPa})$ is anticipated due to strain compensation and $\mathrm{Si}_{x} \mathrm{O}_{2}$ can also work as a barrier against $\mathrm{SrF}_{2}$ thermal stress. Although we do not have the capability to directly measure these stress states at the annealing temperature, our simple calculations provide rough estimates of the stress values. The thermal stress of bilayer dielectrics can be further reduced by engineering the initial stress levels of each film. Deposition of higher compressive stress $\mathrm{SiO}_{2}$ $\left(\sigma_{\text {in }}<-0.2 \mathrm{GPa}\right)$ would decrease the high temperature strain of $\mathrm{SiO}_{2}$ film. Another approach is to deposit $\mathrm{SrF}_{2}$ films at high temperatures (i.e. $500{ }^{\circ} \mathrm{C}$ ) that would provide tensile stressed $\mathrm{SrF}_{2}$ films at room temperature $\left(\sigma_{\text {in }} \sim+1.0 \mathrm{GPa}\right)$ and reduce its total stress to $\sigma_{\text {total,SrF }} \sim-1.1 \mathrm{GPa}$. By employing tensile stressed $\mathrm{SrF}_{2}$ in bilayer films, total compressive stress generated during the thermal process would reduce to $-0.7 \mathrm{GPa}$, which is $-1.7 \mathrm{GPa}$ in the current bilayer films. Such detailed stress engineering study and its effect on QWI selectivity and semiconductor laser performance will be the subject of future work. The effect of the reduced thermal stress and protection of epitaxy by employing 2-layer compared to 1-layer film is reflected in the significant difference in AFM images (figure 2(b)), where highquality surface morphology is obtained by 2-layer films. The consequence of bilayer approach is first studied by PL characterization and then elaborated further by device performance results of high power semiconductor lasers.

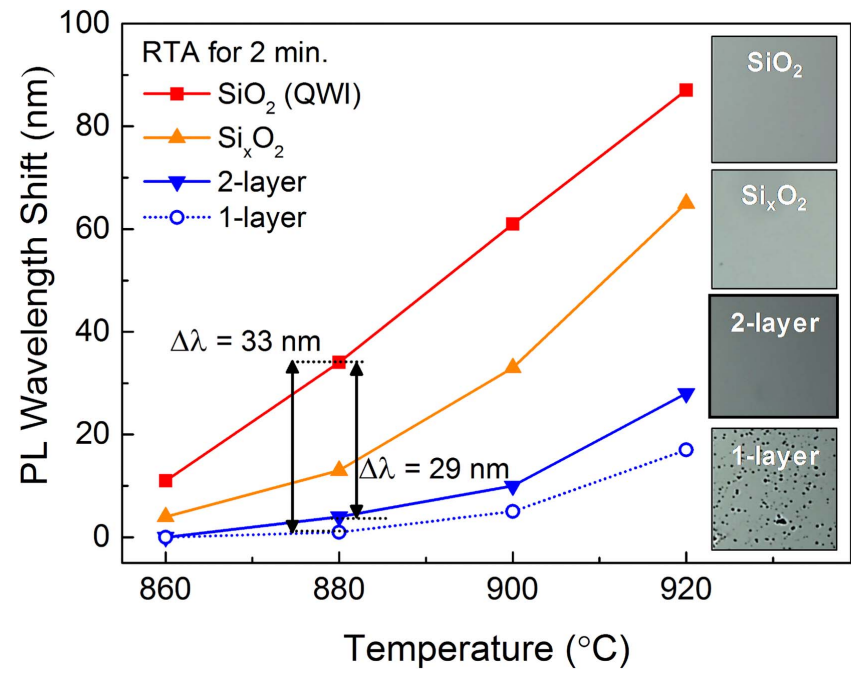

Figure 2. PL peak wavelength shift under annealing conditions of $860{ }^{\circ} \mathrm{C}-920^{\circ} \mathrm{C}$ for $2 \mathrm{~min}$. Inset shows optical micrographs of the semiconductor surface after annealing and removal of dielectrics.

Figure 2 shows the shift of the PL peak wavelength for $250 \mathrm{~nm}$ thick $\mathrm{SiO}_{2}$ and $\mathrm{Si}_{x} \mathrm{O}_{2}$ versus 1-layer and 2-layer capped samples relative to the as-grown structure for annealing temperatures from $860^{\circ} \mathrm{C}$ to $920^{\circ} \mathrm{C}$ for $2 \mathrm{~min}$. The thickness of the dielectric cap strongly affects the blue shift [35]. For both $\mathrm{SiO}_{2}$ and $\mathrm{Si}_{x} \mathrm{O}_{2}$ layers, we found that thicknesses above $250 \mathrm{~nm}$ were enough to saturate QWI wavelength shift in our structure. Hence, for $250 \mathrm{~nm} \mathrm{SiO}$, the additional dielectric layers deposited on it did not affect its QWI behavior. 1-layer and 2-layer deposited samples clearly show that the QWI is strongly suppressed with respect to the oxide capped case. At $880^{\circ} \mathrm{C}$, QWI selectivity was around $33 \mathrm{~nm}$ for a 1-layer film, whereas it decreases slightly to $29 \mathrm{~nm}$ for a 2-layer film. There is no substantial change in FWHM of the PL samples (not shown) indicating that the QW thickness homogeneity is preserved for both QWI and suppression regions.

\subsection{Optimization of the intermixing selectivity}

Figure 3 displays the effect of extended time RTA at $880{ }^{\circ} \mathrm{C}$ on PL wavelength shifts. It shows that the amount of QWI selectivity increases with annealing time because of the shift in QWI wavelength and the wavelength stays almost constant in the suppression region up to $6 \mathrm{~min}$ annealing. Longer annealing introduces more vacancies provided by the $\mathrm{SiO}_{2}$ layer to enhance intermixing. However, the duration and temperature of RTA are not sufficient to cause disordering in the 2-layer region so that its PL wavelength is preserved. Intermixing selectivity of $75 \mathrm{~nm}(125 \mathrm{meV})$ was achieved for 


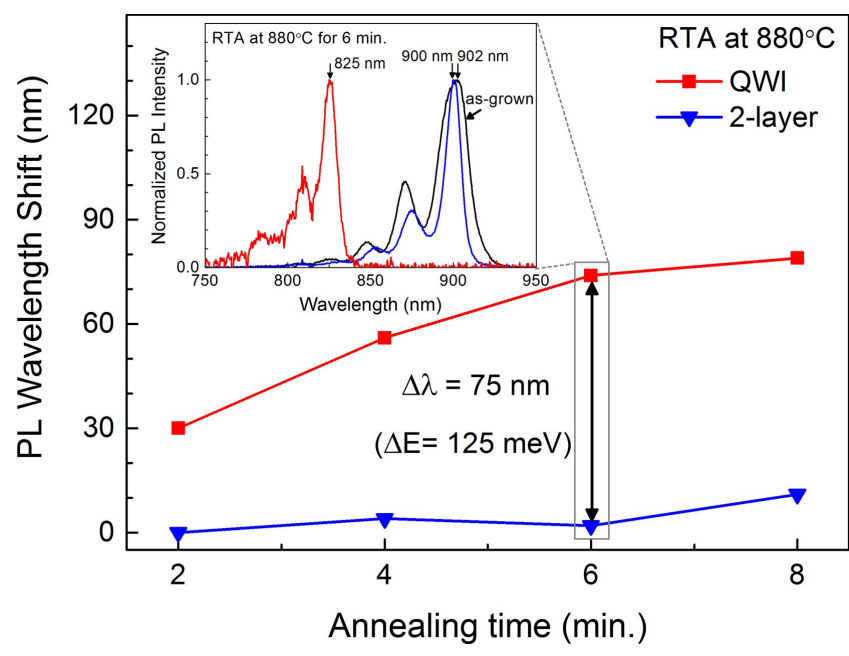

Figure 3. PL peak wavelength shift under annealing conditions of 2-8 min at $880{ }^{\circ} \mathrm{C}$. Inset shows the PL spectrum of QWI and 2-layer suppression regions after annealing at $880{ }^{\circ} \mathrm{C}$ for 6 min compared to as-grown structure.

6 min annealing above which the QWI region show small wavelength shift improvement with the additional time whereas the suppression region PL wavelength starts shifting. This suggests that modification of the QW potential distribution saturates most likely because a finite number of point defects in the QW material composition largely reaches equilibrium. The inset figure shows the PL spectra of QWI and 2-layer capped regions for $6 \mathrm{~min}$ annealing. The 2-layer region spectrum blue shifts slightly but its linewidth and QW state separations are clearly reduced. The smaller quantum state separation may be attributed to QW profile modification (e.g. Gaussian-like instead of square-like) after RTA process [36] producing smaller separations. In QWI region, the inset shows that the PL spectrum starts to smear with indistinct quantum states of the QW.

The effect of diffusion process on the compositional profiles of the barrier and QW after annealing has been reported experimentally [36] and can be examined theoretically by one-dimensional interdiffusion model following the Fick's law $[15,37]$. The concentration $\operatorname{Al}(x)$ variation along the $\mathrm{QW}$ direction $x$ can be expressed by the diffusion equation given by

$$
\begin{aligned}
\mathrm{Al}(x)= & \mathrm{Al}_{\mathrm{bar}}\left[1+\frac{1}{2} \operatorname{erf}\left(\frac{x-d_{\mathrm{QW}} / 2}{2 L_{\mathrm{D}}}\right)\right. \\
& \left.-\frac{1}{2} \operatorname{erf}\left(\frac{x+d_{\mathrm{QW}} / 2}{2 L_{\mathrm{D}}}\right)\right],
\end{aligned}
$$

where $\mathrm{Al}_{\text {bar }}$ is the initial $\mathrm{Al}$ composition in the barrier, $\operatorname{erf}(x)$ is the Gauss error function and $d_{\mathrm{QW}}$ is the $\mathrm{QW}$ thickness. The diffusion length is defined as $L_{\mathrm{D}}=\sqrt{D t}$, where $D$ is the diffusion coefficient and $t$ is the annealing time. The diffusion coefficient is a function of temperature, $T$, and given by $D(T)=D_{0} \exp \left(-E_{\mathrm{a}} / k T\right)$, where $D_{0}$ is diffusion constant, $E_{\mathrm{a}}$ is activation energy and $k$ is the Boltzmann constant.

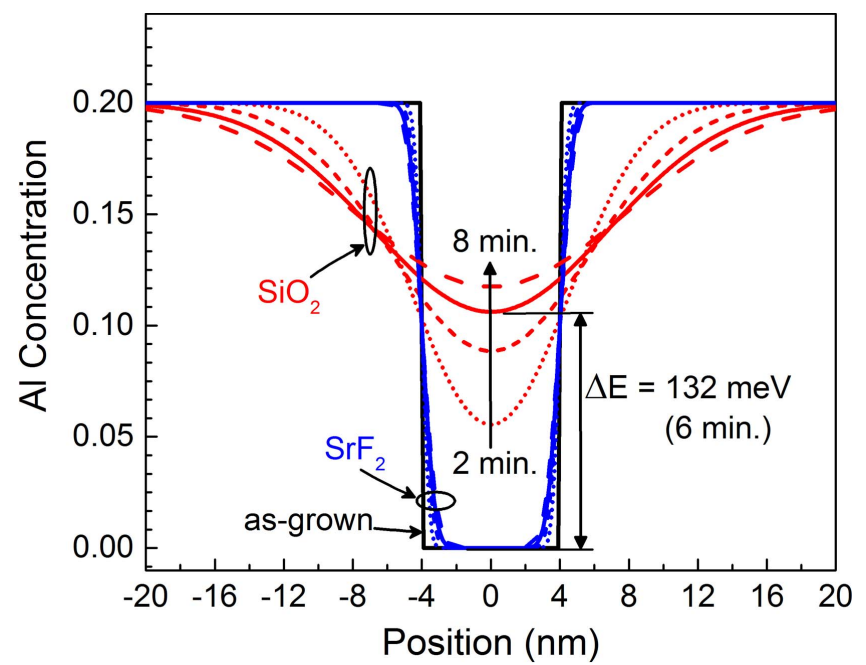

Figure 4. Simulation results of the change in aluminum concentration profile around the InGaAs QW in $\mathrm{SiO}_{2}$ and $\mathrm{SrF}_{2}$ regions for 2, 4,6 and $8 \mathrm{~min}$ annealing at $880^{\circ} \mathrm{C}$ compared to the as-grown profile.

Interdiffusion occurs across the AlGaAs barrier layer and InGaAs QW. The diffusion coefficient of In with low In content of $\sim 0.08$ is assumed to be smaller compared to that of $\mathrm{Al}$ and $\mathrm{Ga}$ so that only $\mathrm{Al}-\mathrm{Ga}$ interdiffusion is taken into consideration in our modeling. The diffusion equation can be applied to the barrier/QW/barrier structure with $E_{\mathrm{a}}=4.09 \mathrm{eV}$ and $D_{0}=427 \mathrm{~cm}^{2} \mathrm{~s}^{-1}$ for the QWI region and with $E_{\mathrm{a}}=6.40 \mathrm{eV}$ and $D_{0}=4.4 \times 10^{10} \mathrm{~cm}^{2} \mathrm{~s}^{-1}$ for the suppression region [15]. This leads to diffusion coefficients of $D_{\mathrm{QWI}}=5.66 \times 10^{-16} \mathrm{~cm}^{2} \mathrm{~s}^{-1}$ and $D_{\text {supp. }}=$ $4.61 \times 10^{-18} \mathrm{~cm}^{2} \mathrm{~s}^{-1}$ at $880^{\circ} \mathrm{C}$, where the diffusion coefficient is around two orders of magnitude smaller in the suppression region. Diffusion parameters of $\mathrm{SrF}_{2}$ capping are assumed for $\mathrm{Si}_{x} \mathrm{O}_{2} / \mathrm{SrF}_{2}$ deposited suppression region since comparable PL shifts were realized as shown in figure 2 . The diffusion equation was solved to calculate $\mathrm{Al}$ concentration profile along the direction normal to the $8 \mathrm{~nm}$ thick QW by modeling diffusion of $\mathrm{Al}$ into and $\mathrm{Ga}$ out of the QW. Figure 4 shows the simulation data for $\mathrm{Al}$ concentration across the barrier and QW in QWI $\left(\mathrm{SiO}_{2}\right)$ and suppression regions $\left(\mathrm{SrF}_{2}\right)$ for $2,4,6$ and $8 \mathrm{~min}$ annealing at $880^{\circ} \mathrm{C}$ together with the as-grown profile. In the simulations, a simple model with $\mathrm{In}_{0.08} \mathrm{Ga}_{0.90} \mathrm{As} \mathrm{QW}, \mathrm{Al}_{0.20} \mathrm{Ga}_{0.80} \mathrm{As} \mathrm{QW}$ barriers as in the laser structure and $\mathrm{SiO}_{2}, \mathrm{SrF}_{2}$ single dielectric layers as in the experiments (but as infinite thickness sources) are assumed to calculate the bandgap profiles due to the IFVD process [15]. The variation of $\mathrm{Al}$ concentration modifies the bandgap, $\Delta E_{\mathrm{g}}(x)=1247 \mathrm{Al}(x)$ in $\mathrm{meV}$ [37]. With a simplified assumption, the wavelength shift approximately follows the QW band gap at the center position, and thus the Al concentration increase to $x=0.106$ at the center of the QW in the IFVD region corresponds to a band gap shift of $132 \mathrm{meV}$. This matches agreeably well with the experimental PL shift difference of $125 \mathrm{meV}$ in figure 3 for $6 \mathrm{~min}$ annealing at $880^{\circ} \mathrm{C}$. Consistent with the experimental results, the simulations demonstrate that the increase of the bandgap shift is 


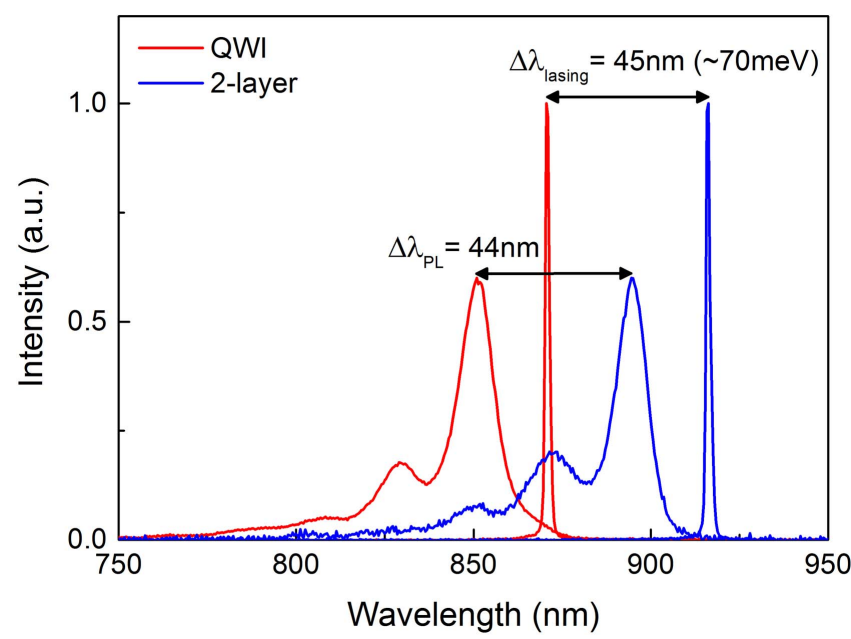

Figure 5. PL and lasing spectrum of the 2-layer and QWI regions with $4 \mathrm{~min}$ annealing at $880^{\circ} \mathrm{C}$.

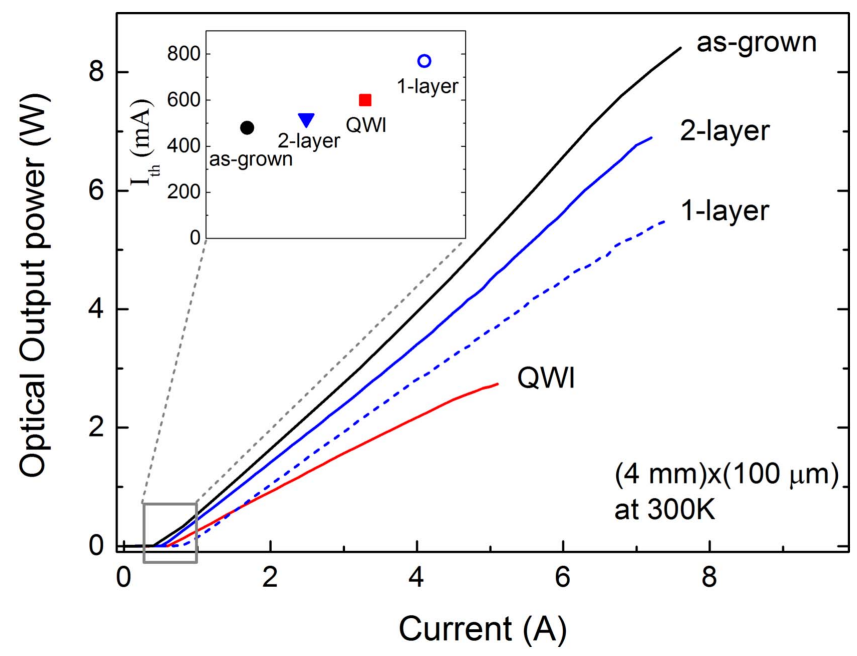

Figure 6. Laser output power as a function of current for the asgrown structure compared to IFVD processed (4 min annealing at $880^{\circ} \mathrm{C}$ ) structures with 2-layer protection, 1-layer protection, and QWI lasers. The inset shows their threshold current.

primarily due to QWI under $\mathrm{SiO}_{2}$ and change of $\mathrm{Al}$ concentration saturates with the increase of annealing time. For the $\mathrm{SrF}_{2}$ region, the $\mathrm{Al}$ concentration in the center of the $\mathrm{QW}$ was calculated to be unaffected but $\mathrm{Al}$ composition and thus the bandgap increases towards the edge of the QW. This would indicate PL peak shift to a slightly shorter wavelength and smaller QW state separations than that of the as-grown QW, which are consistent with the spectral data for 2-layer PL in figure 3 inset.

\subsection{Application to high power semiconductor lasers}

Based on the processes described above, broad area laser diodes were fabricated. Figure 5 shows the PL and lasing spectrum for the QWI and 2-layer capped waveguide lasers with $\sim 45 \mathrm{~nm}$ (equivalent to $70 \mathrm{meV}$ ) difference in the emission wavelength after $4 \mathrm{~min}$ annealing at $880^{\circ} \mathrm{C}$. The peak wavelengths for 1-layer (not shown here) and 2-layer protected lasers are comparable to as-grown devices.

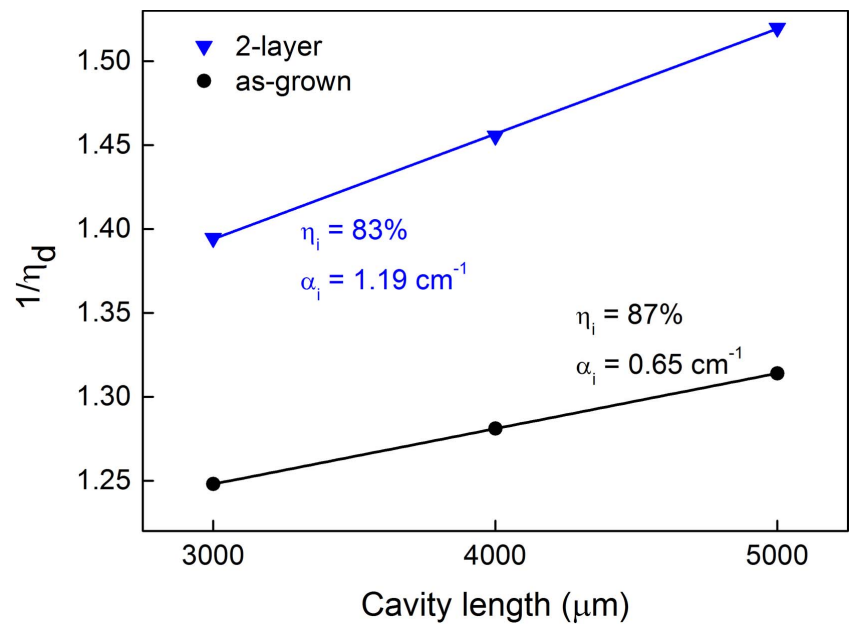

Figure 7. Inverse differential efficiency versus cavity length for as grown and 2-layer protected lasers.

Figure 6 compares the performance of laser devices with as-grown structure and RTA processed waveguides. The lasers are tested epi side up. The slope efficiencies are 1.10, $0.99,0.89$ and $0.65 \mathrm{~W} / \mathrm{A}$ corresponding to a differential quantum efficiency of $81 \%, 74 \%, 66 \%$ and $46 \%$ for asgrown, 2-layer, 1-layer and QWI lasers, respectively. The slope efficiency of the QWI laser degrades the most due to reduced confinement of the carriers as expected. Although 1-layer and 2-layer capped lasers have similar PL and lasing wavelengths, 2-layer protected device demonstrates much better slope efficiency compared to the 1-layer case. The inset of figure 6 shows the lasing threshold currents of the same devices, which are 480, 520, 600 and $770 \mathrm{~mA}$ for as grown, 2-layer, QWI, and 1-layer capped lasers, respectively. The threshold current of 1-layer protected laser is $60 \%$ higher than as-grown device whereas the increase is only $8 \%$ for 2-layer protected laser. Both slope efficiency and threshold performance penalty verify the degradation of epitaxial quality for the 1-layer device and better performance results using the 2-layer protection.

In order to further investigate the effect of 2-layer suppression on laser performance, internal quantum efficiency and internal loss were characterized by using reciprocal differential efficiency versus cavity length method [38]. The results are depicted in figure 7 comparing RTA processed 2-layer protected and as-grown devices. For as-grown lasers, the internal quantum efficiency and internal loss were measured as $87 \%$ and $0.65 \mathrm{~cm}^{-1}$, respectively. For 2-layer capped lasers, the internal quantum efficiency and loss degraded slightly to $83 \%$ and $1.19 \mathrm{~cm}^{-1}$. The internal loss increase is probably associated with the increase in the scattering losses through rough interfaces. Although 2-layer dielectric has much lower thermal stress compared to 1-layer film and it did not show any sign of epitaxial defects in AFM images, it still has large thermal stress. This stress might create rough interfaces and increase the scattering loss of the optical waveguide. For 1-layer capped lasers, we were not able to measure the internal quantum efficiency and loss parameters consistently and devices usually failed at low power levels. 
However, 2-layer capped lasers exhibited similar and repeatable performance for various devices tested in this study signifying the impact of dielectric stress management of the IFVD process on laser performance.

\section{Summary}

In summary, we have demonstrated, for the first time, the impact of thermal stress generated by the dielectric capping layers during the IFVD process on the quantum efficiency and performance of optoelectronic devices. IFVD based QWI by $\mathrm{SiO}_{2}$ and intermixing suppression by bilayer films of $\mathrm{Si}_{x} \mathrm{O}_{2} / \mathrm{SrF}_{2}$ provided large intermixing selectivity of $75 \mathrm{~nm}$ $(125 \mathrm{meV})$ with excellent surface morphology. Utilizing a bilayer dielectric with lower thermal stress strongly reduced the detrimental impact of the high-CTE $\mathrm{SrF}_{2}$ film without sacrificing its QWI suppression benefits. High power laser diodes using bilayer dielectric films outperformed single-layer based approach in terms of the fundamental operational parameters of lasers. By engineering the intrinsic stress of dielectric bilayers during deposition, it is possible to reduce the thermal stress effect on IFVD process, dramatically. To achieve better performance with bilayer dielectrics, its thermal stress can further be reduced by engineering the initial stress levels of each film, i.e. by deposition of higher compressively stressed $\mathrm{SiO}_{2}$ and tensile stressed $\mathrm{SrF}_{2}$ dielectrics. Thermal stress engineering opens new perspectives in IFVD that would make it possible to realize large QWI selectivity together with conservation of quantum efficiency and reliable optoelectronic device performance.

\section{Acknowledgments}

The financial support of Ermaksan A.Ş. is gratefully acknowledged. The authors would like to thank Rahim Bahari Qushchi for his help in spectroscopic ellipsometry measurement.

\section{ORCID iDs}

Abdullah Demir (1D https://orcid.org/0000-0003-4678-0084

\section{References}

[1] Wenzel H, Crump P, Pietrzak A, Wang X, Erbert G and Tränkle G 2010 New J. Phys. 12085007

[2] Demir A, Peters M, Duesterberg R, Rossin V and Zucker E 2015 IEEE Photon. Technol. Lett. 272178

[3] Demir A, Peters M, Duesterberg R, Rossin V and Zucker E 2015 Proc. SPIE 9348 93480G

[4] Demir A and Peters M 2017 US Patent 9647416 https://www. google.com/patents/US9647416

[5] Ziegler M, Hempel M, Larsen H E, Tomm J W, Andersen P E, Clausen S, Elliott S N and Elsaesser T 2010 Appl. Phys. Lett. 97231101
[6] Epperlein P W 2013 Semiconductor Laser Engineering, Reliability and Diagnostics: A Practical Approach to High Power and Single Mode Devices (UK: Wiley) ch 4

[7] Ooi B S, McIlvaney K, Street M W, Helmy A S, Ayling S G, Bryce A C, Marsh J H and Roberts J S 1997 IEEE J. Quantum Electron. 331784

[8] Furtado M T, Loural M S S, Sato E A and Sacilotti M A 1992 Semicond. Sci. Technol. 7744

[9] Du S C, Fu L, Tan H H and Jagadish C 2010 Semicond. Sci. Technol. 25055014

[10] Bryce A C, Camacho F, Cusumano P and Marsh J H 1997 IEEE J. Sel. Top. Quantum Electron. 3885

[11] Zhang X, He J J, Liu N and Dubowski J J 2015 Opt. Express 23247833

[12] Hou L, Haji M, Dylewicz R, Qiu B and Bryce A C 2011 IEEE Photon. Technol. Lett 2382

[13] Yu J S, Song J D, Lee Y T and Lim H 2002 J. Appl. Phys. 921386

[14] Gareso P L, Buda M, Fu L, Tan H H and Jagadish C 2007 Semicond. Sci. Technol. 22988

[15] Gontijo I, Krauss T, Marsh J H and Delarue R M 1994 IEEE J. Quantum Electron. 301189

[16] Yu J S, Song J D, Lee Y T and Lim H 2005 Appl. Phys. A 80847

[17] Kahraman A, Gür E and Aydınlı A 2016 Semicond. Sci. Technol. 31085013

[18] Pepin A, Vieu C, Schneider M, Launois H and Nissim Y 1997 J. Vac. Sci. Technol. B 15142

[19] Morita T, Nagakura T, Torii K, Takauji M, Maeda J, Miyamoto M, Miyajima H and Yoshida H 2013 IEEE J. Selec. Top. Quantum Electron. 1915002104

[20] Naito H, Nagakura T, Torii K, Takauji M, Aoshima H, Morita T, Maeda J and Yoshida H 2015 IEEE Photon. Technol. Lett. 271660

[21] Taniguchi H, Ishii H, Minato R, Ohki Y, Namegaya T and Kasukawa A 2007 IEEE J. Selec. Top. Quantum Electron. 131176

[22] Hofstetter D, Zappe H P, Epler J E and Riel P 1995 Appl. Phys. Lett. 671978

[23] Hofstetter D, Maisenholder B and Zappe H P 1998 IEEE J. Sel. Top. Quantum Electron. 4794

[24] Beauvais J, Marsh J H, Kean A H, Bryce A C and Button C 1992 Electron. Lett. 281670

[25] Chen Y C and Bhattacharya P K 1993 J. Appl. Phys. 737789

[26] Ekins-Daukes N J, Kawaguchi K and Zhang J 2002 Cryst. Growth Des. 2287

[27] Liu X, Zhao W, Xiong L and Liu H 2015 Packaging of High Power Semiconductor Lasers (New York: Springer) pp 89-105

[28] Kash K et al 1988 Appl. Phys. Lett. 53782

[29] Pépin A, Vieu C, Schneider M, Launois H and Nissim Y 1997 J. Vac. Sci. Technol. B 15142

[30] Deenapanray P N K and Jagadish C 2001 Electrochem. SolidState Lett. 4 G11

[31] Al-Jabr A A et al 2016 J. Appl. Phys. 119135703

[32] Roberts R B and White G K 1986 J. Phys. C: Solid State Phys. 197167

[33] Glazov V M and Pashinkin A S 2000 Inorg. Mater. 36225

[34] Ghaderi M, de Graaf G and Wolffenbuttel R F 2016 J. Micromech. Microeng. 26084009

[35] Shimada N, Fukumoto Y, Uemukai M, Suhara T, Nishihara H and Larsson A 2001 IEEE J. Sel. Top. Quantum Electron. 7350

[36] Hulko O, Thompson D A and Simmons J G 2009 Semicond. Sci. Technol. 24045015

[37] Cibert J et al 1986 Appl. Phys. Lett. 49223

[38] Coldren L A, Corzine S W and Masanovic M L 2012 Diode Lasers and Photonic Integrated Circuits 2nd edn (New York: Wiley) p 75 